\title{
The impact of e-learning in the education in the information society
}

\author{
Irina I. Trubina ${ }^{1, *}$ and Anna A. Braines ${ }^{2}$ \\ ${ }^{1}$ ISED RAE, Center of Theory and Teaching Methods of Mathematics and Informatics, 105062, Moscow, Russi \\ ${ }^{2}$ Ministry of Defence, the Boarding school, 125284, Moscow, Russia
}

\begin{abstract}
The article says about the features of the nurturing activities in the information society. Electronic educational resources should be directed towards new educational results. Information technology claims new features, modifies the flow of the mental processes of cognitive activity of students, rebuilds the structure and function and thereby changes the whole structure of the training activities. The essence of the manifestations of education can be determined only after understanding of the essence of the phenomenon of "educational activity". Highlighting its basic features, it is possible to relate them to the presence or absence of specific e-learning resources.
\end{abstract}

The information society is an essential and natural product of the rise of the post-industrial society. According to D. Bell, what distinguishes the postindustrial society is that information (its acquisition, processing, transfer, distribution, dataflow management) becomes the main object of human activities in it [1]. However, the information society is also a result of the production system globalization, of distribution and use of information. This means that only based on globalization processes and in their wake the information society gets established on a global scale, turns into a world-wide human community. Consequently, the construction of the information society just as the current globalization processes moulding post-industrial business activities in the world stem from the same foundation. They have common goals and objectives set and achieved, they face difficulties and inconsistencies of the same type. However, as the predicate of these processes the information society is generated and regenerated due to expanding communications accelerated dissemination of information, its understanding and use. What distinguishes the information society is the continuous impact of communications upon each other, and in this sense the transformation of relevant information and messages relayed from one subject to another. After all, it is actually the processes of communication between various entities (the degree of their comprehension of the received information and the quality of its delivery to others) that both the progress of globalization and the development of the post-industrial society largely depend upon now.

Thus, the information society is not so much determined by the knowledge boost in all areas of human life, but mainly by increased communication, i.e. by human interaction based on circulation of this knowledge and on the arisen opportunity to obtain it fairly quickly (merely by pressing a computer key).

Naturally, the availability of a most varied range of readily obtainable information promotes a wider choice of human behaviours, thus increasing the chances of various activities to be designed and effectively implemented.

Focused on developing the creative potential of a personality the information society is able to determine not only the prospects of man's intellectual improvement but also further development of the knowledge available to entire mankind. However, one cannot but see that for all its benefits the information society not only induces but also augments consumer-like attitude of individuals to the world around, since it promotes utilitarian assessment of any phenomenon, and therefore, generates the hazard of information addiction, of forming an informationally monodimensional human. Moreover, the knowledge environment created by the information society becomes a virtual reality often more significant than the actual reality for some of knowledge bearers.

It is necessary to be able to distinguish between the primary and the secondary aspects in information, to have skills in classifying and systematizing it, to see inherent ties of its various fragments, to learn to turn visual information into verbal one or into any other sign information and vice versa. Only upon mastering these abilities and skills one will be able to effectively configure information and apply it in practice.

It is important to emphasize that one's success in mastering the information culture in modern society increasingly depends on one's sustained interest in a certain piece of information before this piece of information gets generated. That is why one may state that the degree of an individual's effective integration into the modern information society is determined by

\footnotetext{
Corresponding author: uvshp@mail.ru
} 
one's intellectuality, i.e. the vast knowledge and in-depth understanding of the processes reflecting this knowledge. After all, computer systems cannot intelligently function by themselves. This activity in the modern society requires a properly qualified human, i.e. someone with a special training and education. This education should comply with ever-changing reality or else it will not facilitate the social functions assigned to it.

As an activity dedicated to engaging individuals in social life, education includes two closely interrelated processes - nurture and training. Each of these processes has its function in formation and development of the human personality.

For example, in the process of their nurture individuals adopt certain significant spiritual-andpractical ways of making themselves familiar with the world, such as are typical of their environment. It is nurture that not just makes it possible to adjust some desired behaviour or practice of a person in society but also helps him/her to arrange its certain forms under suggested life circumstances. Conversely, in the process of training, a studying person obtains general and specific knowledge of the contemporary picture of the world and designs a meaningful cognitive-andtheoretical way of adapting to the object filled environment. Training creates an object for an individual, forming one's notion of the world around, knowledge of self and the others one lives and interacts with, whereas nurture creates and develops the individual proper for the world around, facilitates formation and development of one's personality features. It is clear that nurture and training mould, create (or at least strive to generate) one's "self" with fully specified properties of behaviour, experience, knowledge, outlook essential for one's life in society only in their unity.

As the most important institution for human socialisation, education directs the compressed meaningful experience of mankind's development to individuals enabling them to internalize it through training and nurture focused not only on reduction but also on proper arrangement of the process of one's socialisation. It reveals to an individual, to all people ways to satisfy their needs, to ensure their well-being, to understand and use their rights, to learn and do their duties.

Nurture has always been researched at macro- and micro-level. The macro-social level reveals the sum total of child socialisation factors. Historically, the range of these factors has undergone considerable changes. Today, such a factor as human communication (Internet, telecommunication systems etc.) has substantially changed, but we should bear in mind that relationships between humans are the most important mechanism of nurture.

The phenomenon of nurture as a specific pedagogical activity is much less researched at the micro-level, e.g. what a pedagogue should do when it is the functions of a nurturer that he/she assumes. The situation of nurture is first of all a situation focused on developing the personality of a pupil; on enabling him/her to function as an individual (attain personal fulfilment). This situation should include such tasks, collisions, factors which challenge the individual being nurtured:

- to make an independent decision on how to behave (there is no nurture, if someone else makes this decision for him/her);

- to act morally (as evidenced by depriving oneself of something, such as time, strength, means, and then consciously, willingly pass it on, dedicate it to another person) [3].

In fact, there is but one type of nurture, viz. moral; all other names such as patriotic, legal, environmental, economic, vocational etc. are only conventional designations of the areas for moral experience to be internalised and be put into practice. A nurturing situation is not an activity but an event, which generates reflection, new moral experience. It is obvious that arranging an activity and designing an event are absolutely different things. The latter implies that the educator has become part of the pupil's life context, is engaged in an interpersonal dialogue with him/her, has involved the pupil in an interesting social project conducive to actions and self-actualization.

The education system model stemming from mutually enriching penetration of an activity-based approach and a knowledge-based approach has been consolidated in the concept of state educational standards of the second generation. The foundation is laid by the thesis that personality development in the system of education is ensured, first and foremost, by formation of universal learning actions (ULAs) in pupils, with these ULAs functioning as the basis for the process of nurture and education.

The main types of universal learning actions determined by key goals of general education are grouped into five sets: personality-oriented, regulatory, cognitive, sign-and-symbol-based and communicative.

Criteria of moulded ULAs in learners are as follows:

- compliance with age- and psychology-related standards;

- compliance of ULA properties with pre-set requirements;

- completeness of the learning activity in learners, which reflects the level of development of metaobject actions intended to control the cognitive activity of learners [2].

Earlier, IT use in class was encouraged yet optional, but with introduction of Federal State Educational Standards educators are actually bound to use information and communication technology in class and to teach students its rational and effective use. Information technologies activate new functions, modify the flow of mental processes within the cognitive activity of learners, rearrange the structure and functions, thereby changing the entire learning activity structure.

E-learning resources deserve special consideration, with reference to creation and use. An e-learning resource (ELR) is an independent, interactive, multipurpose electronic publication, which may include systematized theoretical and/or practical and/or monitoring items using multimedia technology elements.

Modern e-learning resources must be focused on achieving new educational results: 
- to build general study skills and competencies;

- to gain experience in solving life problems on the basis of knowledge and abilities;

- to develop abilities to work with information - to search, assess, select, arrange information;

- to establish project activity skills and expertise in appraising the results of accumulated material;

- to build project activity skills including the conduct of actual and virtual experiments;

- to develop skills in independent study and assessment of one's behaviour results, decision making in a non-standard situation;

- to build team-work skills, abilities to correlate and coordinate one's actions with those of others, to conduct reflection and discussion.

The nurturing effect of e-learning is determined by the place assigned to learning as an area of life in the learner's general system of values, by how and what for he/she learns, by how learning is ranked among the dominating factors of development, within the meaningof-life system.

Man has been known to obtain information from two main sources:

- direct perception of an object via sense organs;

- description of these objects.

However, as I. Kant argued, there are always ideal, a priori objects present in human mind, which always, independently of a person, get involved in the process of shaping views of an object under study. Of course, in itself the human "direct perception" of some object may strongly vary. It may depend on many factors, such as place and time, internal state of a person, his/her knowledge and psychological peculiarities, tools and instruments used, etc. Nevertheless, in all cases, direct perception of an object can always be contrasted with its description.

Balanced use of the above two sources has been customary for the national education. A well-developed system of laboratory work classes was established, as well as manual labour classes, which played a very substantial role in developing the sense of reality. The situation changed radically with information civilization progress. A modern individual receives information, largely, through descriptions, very often via Internet. The fact has been recorded in all educational documents without exception. For instance, in UK it is conventional to set forth the following requirements:

- systematic use of information to solve problems, answer questions;

- use of information search methods consistent with a set goal;

- selection, qualitative and quantitative evaluation of information;

- systematization of information.

All the above requirements are certainly very important for successful activity. However, in our opinion, these are just necessary but not sufficient conditions for this activity.

The problem seems to be in the operational nature of the information circulating in modern society. Such information is not meant to be integrated into a certain system of views of a given object, but only serves to support an immediate response ("fix it and forget it").

Of course, tackling complex life problems requires a profound and continuous analysis of all the incoming information rather than just reflex actions. Traditionally, the standards of such analysis are traced back to fundamental sciences, primarily to mathematics and physics. The fact was emphasized early on by M.V.Lomonosov, who argued that, for example, the importance of mathematics was, among other things, in "putting one's mind in order." In addition to the subject matter, the said disciplines set general principles, which can serve as guidelines for evaluation and analysis of information. These principles are typically not discussed in the context of the relevant academic subjects. However, these principles seem to be very important as a tool for structuring the operational information and are essential for transforming it into knowledge.

Furthermore, such principles seem to be essential in developing an information science syllabus meant to meet students' need to cognise the world around, in nurturing scientific conceptions, and must be explicitly formulated.

These principles include:

- the principle of reductionism;

- the principle of systematicity;

- the principle of symmetry and the related laws of conservation;

- the principle of uncertainty and the related principle of complementarity;

- the principle of incompleteness;

- the principle of considering inter-system communication.

One of the most important purposes of general scientific principles is pushing the scope of world cognition beyond the limits of direct perception or, in terms of information science, towards obtaining the maximum amount of information about the external world. By way of illustration, the principle of symmetry tells us that the laws of nature in remote parts of the universe are the same as in our solar system. This principle underpins all achievements of contemporary cosmology.

The role of such principles in establishing one's world outlook and forming the analytical component of a professional activity is immense. They do not only set a certain "matrix" of understanding the world, but are also implemented in various human activities. The way a person solves a problem depends not only on specific knowledge and competencies but also on his/her prestructured world view.

This information environment is exceptionally dynamic. In terms of a systemic approach it is an open system obeying the law of non-linear dynamics (I. Prigogine, H. Haken et al.). The dynamic is characterized by appearance of the so-called "bifurcation points" where the deterministic process branches. Moreover, there is no telling which way the process is going to follow. It is impossible to "nest" such processes in any automatic routine, i.e. there is no chance of coming across a required algorithm. An ability to take decisions i.e. to choose either branch of the process on 
the basis of a current situation analysis becomes critical in this case.

To this end, one must have an adequate understanding of the information environment containing this information process and, in a more general case, have an understanding of the information picture of the world at large. In this case reflecting on information activity is possible in the broadest context to add precision to the prediction about options of the process further development. This, in turn, requires comprehending the process of problem solving as such.

The information technology the students learn has conventionally been but an "algorithmic" part of the described process flow. However, information systems based on information technologies are overwhelmingly open and characterized by extremely unstable dynamics. Specifically, these systems, as stated above, may contain bifurcation points. E. g., most economic systems are of this kind. In this context it is utterly impossible to program the behaviour of a process. Accordingly, reducing a problem-solving procedure to developing and implementing an algorithm or to using standard information technologies produces little effect.

In an open system, information technology with its models building and evaluating element is more adequate. This enables reflecting on current activities and consequently shaping a skill in making decisions on choosing either way of further information activity.

A number of studies (S.A. Beshenkov, E.A. Rakitina, K.K. Kolin et al.) have shown that evaluation of models is based on general conceptions associated with a currently accepted vision of the world. Thus, the problem-solving information technology in an open information system must include a stage of addressing the general information conceptions. These conceptions form a context necessary for making decisions on choosing the way for further information activity.

It should be noted that integration of various ways humans learn the world, development of systemic, holistic processes in science, philosophy and practice are yet to be adequately reflected in contemporary education. Further subject differentiation of scientific knowledge is taking place as a means of attaining to efficiency of learning and teaching. The entire system of education, as ruefully observed by contemporary researchers, simply replicates the increasing differentiation of science and strives to embrace the nonembraceable. Narrow specialisation and professionalisation generated partial, disrupted knowledge, detached from man. Along with getting ready-made differentiated knowledge students also adopt a reproductive pattern of thinking. Thus, development of creativity in the system of information-related training of students is directly linked to forming their conceptions of contemporary scientific view of the world.

According to contemporary studies conducted at the Russian Academy of Sciences Institute of Informatics Problems (I.M. Gurevich, R.B. Seiful-Mulyukov, R.S. Gilyarevsky et al.) this system's main features are as follows:
- it is the least complex variant of a system that is realized, survives, gets selected (the law of simplicity of complex systems);

- the rate of interaction between elements and individual parts of a system is finite (the law of finiteness of complex systems characteristics);

- for a system to function effectively the variety of its controller needs to be at least matching the variety of its controlled object (Ashby's law of requisite variety);

- it is the form of a system's development which maximises information growth in the system that gets realized (Onsager's law of entropy reduction maximization);

- an external input shifting the equilibrium of a system generates processes therein to reduce the imposed changes (Le Chatelier's principle).

Relying on these principles paves the way for education focussed on implementation of educative potential of information technologies and on shaping individuals capable of finding their bearings and making reasonable decisions in contemporary information environment.

Nurture in the structure of the integrated educational process is distinctly peculiar as a specific function of education - the pedagogical activity type focused on enabling a pupil to accept the situation of education as the main avenue of his/her personal ontogenesis at a given stage of life. Nurture related activities in a comprehensive school are focused on creating an environment, which enables learners to gain the meanings of responsible, proactive and creative attitude to education, and to transfer the learning experience to all other areas of their own lives.

The effective use of e-learning resources in class is ensured by the following:

1. Multimedia environment

2. Modelling

3. Interactive mode

Multimedia environment offers a solution for simultaneous audio and visual display of a set of variously represented objects using a computer monitor. The quality of a multimedia product depends on how adequately a real world fragment is represented. Its ultimate manifestation is virtual reality using multimedia components boasting the quality taken to the limits of human perception: 3D visualization and stereophonic sound.

Modelling is a simulation modelling with audiovisual reflection of changes in the essence, type, qualities of objects and processes. An e-learning resource can offer a proper representation of a fragment of the real or imaginary world instead of a description in symbolic abstractions. Using a computer one can simulate a lot of actions and have lifelike effects of an individual's actions displayed on the computer monitor.

Interactivity is expressed in the possibility of interaction of a user with the content of an e-learning resource, in the use of proactive forms of learning. The subject matter content in interactive ELRs is represented by specific objects suitable for manipulation and by processes open for intervention (e.g. a laboratory 
experiment, knowledge monitoring with assessment and conclusions, etc.).

The sector of independent learning is expanded as a result of integration of computer technology into the educational process. Interactivity is the fundamental novelty in this case.

This promotes expansion of the set of functions of independent learning essential in terms of education goals and efficient in terms of time input.

Accordingly, substituting ELR interactive content for a text fragment with information for independent learning should improve the quality of the educational process organisation.

Now, how can one assess the nurturing aspect of some ELR or other?

The essence of the nurture manifestation can be identified only through grasping the main point of the "nurturing activity" phenomenon itself. Having identified its basic signs one can correlate their availability or non-availability in specific e-learning resources.

1. Availability of special circumstances in e-learning resources (either artificial or objective) under which the person engaged in the process is required to make a spiritual effort aimed at self-identification, which includes assuming some responsibility, making a choice, defining one's manner of behaviour, etc.

2.It is necessary to identify sense forming points, such as specially arranged events determining the attitude of the individual being nurtured to education among other things.

3. To offer the individual being nurtured positive spiritual and moral examples of ways and meanings of life.

4. Designing a situation of nurture is not developing an event but collaboration of the pedagogue and the person being nurtured in solving some problems meaningful for the learner.

5. Dialogue with a pedagogue is the primary environment for moral experience. The 'pedagogue' is not necessarily meant to be a teacher but could be anyone performing this function.

6 . The process of nurture is focused on developing the pupil's subjective identity, which manifests itself in him/her becoming the only master expert of his/her life to accept or reject statements or stances.

7. A mode of behaviour cannot be imparted by mere informing; one needs to go through an event, to gain new experience on one's own.

8. What the pupil does an activity for is more important than how he/she does it with reference to success. Support of the personality's notional sphere, moral attitude to everything that is socially significant.

9. Place the learner in situations enabling and challenging him/her to reveal his/her moral strength, to literally share with others by depriving himself/herself of something.

10. Continuous appeal to the personality's emotional and moral sphere, to its civilian, patriotic, aesthetic, ethnocultural, kinship and other emotions and feelings. Not exploiting but cultivating them.
Personality in the information society is primarily developed through cultivation of ULAs, which function as an invariant basis for the process of education and nurture.

Universal learning actions promote successful acquisition of new knowledge, abilities and competencies including organisation of internalisation, i.e. the ability to learn.

The nurturing aspect is related to involving a pupil in meaningful events conducive to positive new constructs in his/her moral experience

\section{References}

1. D Bell, The Coming of Post-Industrial Society (New York, 1973.)

2. S.A. Beshenkov, I.I. Trubina, and E.V. Mindzayeva, Razvitiye universalnykh uchebnykh deistviy $v$ obscheobrazovatelnom kurse informatiki (Izd-vo KRIPKiPRO, Kemerovo, 2010) [In Rus]

3. V.V. Serikov, Razvitiye lichnosti v obrazovatelnom protsesse: monographiya (Logos, Moscow, 2012) [In Rus] 